\title{
Moralization of Religiosity Explains Worldwide Trends in Religious Belief
}

\author{
Samantha Abrams $^{1 *}$, Joshua Conrad Jackson ${ }^{1}$, Andrew J. Vonasch ${ }^{2}$, Kurt Gray ${ }^{1}$
}

1. Department of Psychology and Neuroscience, University of North Carolina at Chapel Hill, Chapel Hill, USA

2. Department of Psychology, University of Canterbury, Christchurch, New Zealand

*Correspondence should be addressed to srabrams@email.unc.edu

\begin{abstract}
Religion is an enduring part of human culture, but religious belief is declining in some societies. What explains which regions secularize and which individuals leave their faiths? We propose that secularization is inversely related to the "moralization of religion:" the belief that religion is essential to morality. Moralization of religiosity likely emerged as a by-product of the historical rise of prosocial religions, but we propose that it has an additional side-effect - it discourages deconversion due to perceived reputational costs. We further suggest that cultural differences in the moralization of religiosity foreshadow patterns of nation-level secularization and individual-level deconversion. Our model is supported by historical cross-cultural, retrospective longitudinal, survey, and experimental studies $(N=221,202)$, which show that the moralization of religiosity inhibits both secularization across nations and deconversion across individuals, and also fosters prejudice against nonbelievers.
\end{abstract}

Keywords: Religious Belief, Morality, Secularization, Culture 


\section{Moralization of Religiosity Explains Worldwide Trends in Religious Belief}

Humans have practiced religion for thousands of years. Throughout history, religious beliefs have motivated people to build monumental temples and shrines, travel on long pilgrimages, and fight bloody faith-based wars. But in some places, these convictions are beginning to wane. The proportion of Americans identifying as "nonreligious" has grown from $1 \%$ in 1957 to $20 \%$ today [1], and this number is over $60 \%$ in some European nations [2]. On the other hand, over $90 \%$ of people in Greece, Poland, and Brazil still identify as religious [2]. These different trends raise important questions about the trajectory of religious belief. Why are people deconverting now, after so many years of religious ubiquity? And why are some nations secularizing faster than others? Here we introduce a new model of secularization that addresses these questions by focusing on the historical development of religion, and in particular, the perceived fusion between religion and morality.

To understand these diverging patterns of religious belief, we first consider how modern religions first developed and rose to prominence. Theories of cultural evolution suggest that prosocial religions featuring moral codes and watchful, punitive gods became increasingly common during the Neolithic Revolution as humans began living in larger agriculture-based groups that lacked the secular authorities that could enforce cooperation [3-7]. According to these theories, prosocial religions could reduce free-riding and promote prosociality in these communities by cultivating people's fear that antisocial and selfish behavior would be met with divine retribution [3-7]. Perhaps because of these social functions, prosocial religions spread rapidly around the world, and most current-day world religions feature moral codes (e.g., the Judeo-Christian Ten Commandments, the Buddhist Five Precepts) and supernatural punishment for people who violate these codes (e.g., hell, karmic punishment) [8]. The cooperationenhancing consequences of punitive religious beliefs may have fueled the rise of prosocial religions, but the merging of religion and morality may also explain why religious belief has persisted into the modern era.

We propose that prosocial religions may have long inhibited secularization because they not only moralize cooperation but religious belief itself. Specifically, we suggest that the belief that religion is necessary for morality - i.e., the moralization of religiosity - inhibits the loss of religion, and that the strength of this belief can explain individual and cultural variation in religiosity. The moralization of religiosity is remarkably common; almost half of the world's population agrees that belief in God is necessary to be a good person [9]. Since people are highly motivated to protect their moral reputation [10] and to see themselves as morally virtuous [11], the moralization of religiosity may have historically been a powerful obstacle for individuals abandoning their religious beliefs (i.e., deconversion) and for groups to become less religious (i.e., secularization). For this same reason, the moralization of religiosity may also explain why Atheists are commonly viewed as untrustworthy [12-13] and are universally seen as more likely than religious people to commit immoral acts [14].

While the moralization of religiosity might have been a powerful deterrent to deconversion as large-scale societies first emerged, it has steadily declined in many countries, falling to rates as low as 39\% in Japan and $15 \%$ in France [9]. As countries develop stable secular authorities and organized judicial systems, people may see religion as less critical for cultivating morality. We propose that, in these nations, people should feel less guilty about deconverting and should perceive less of a reputational cost to deconversion, since losing religion does not necessarily mean losing one's moral standing. Cross-cultural differences in the 
moralization of religiosity should therefore predict the future likelihood of secularization, and individuals' endorsement of this belief should predict their future likelihood of deconverting.

The moralization of religiosity has the potential to answer other open questions about secularization and deconversion. For example, sociologists emphasize that broad sociocultural factors like wealth and inequality predict secularization [15-16], yet these models do not explain why nations such as the United States - which strongly moralizes religion - are more religious than similarly wealthy countries [9]. On the other hand, psychologists study individual motivations for religious belief such as death anxiety [17], loneliness [18], and lack of control [19], yet these individual-level factors do not always correlate with religious belief [20-21] and are less suited to explaining cross-cultural variation in secularization since they focus on human universals. Our model bridges these disparate approaches by proposing a single construct - the moralization of religiosity - that can explain loss of religion among both individuals and societies. Specifically, we predict that the moralization of religiosity should predict 1) crosscultural variation in secularization, even controlling for sociological factors such as inequality and economic development, and 2) individual-level variation in willingness to deconvert, even controlling for psychological factors like death anxiety, need for control, and loneliness.

Across five studies, we test whether moralization of religiosity motivates resistance to nation-level secularization (Study 1) and individual-level deconversion (Studies 2-5). We test this hypothesis across countries and individuals in a methodologically diverse set of studies $(N=$ 221,202). Our studies also test the role of moral reputation concerns in this relationship by examining whether people who deconvert experience a loss of moral standing (Study 2), whether the moralization of religiosity can predict people's anticipated guilt about deconverting (Study 3), and whether people will ostracize and be prejudiced toward nonbelievers (Study 4). Study 5 replicates our key findings with an experimental design and causal inferences.

\section{Results \\ Study 1: Cross-Cultural Variation in Secularization}

Study 1 tested whether cross-nation differences in the moralization of religiosity in 19811995 foreshadowed countries' secularization from 1995-2014. We obtained data on moralization of religiosity and secularization from the World Values Survey (WVS), which has collected and made available six waves of data from 1981 to 2014. We indexed cross-cultural variation in the moralization of religiosity using a composite index of moralizing religious beliefs, which included beliefs in the Devil, sin, and hell. A nation-level score of 100 on this composite measure would indicate that $100 \%$ of people in the nation's sample held these beliefs, whereas a nationlevel score of 0 would mean that nobody in the nation's sample held any of these beliefs. While moralizing religious beliefs do not necessarily imply the moralization of belief itself, they imply that people view religion as a moralizing force, which is an important prerequisite for the moralization of religiosity. A pilot study summarized in our supplemental materials (SM) also confirmed that belief in sin, the Devil, and hell strongly predicted the moralization of religiosity above and beyond other religious beliefs (see Study S1).

We indexed rates of secularization using data on religious participation (i.e., frequency of service attendance) and identification (i.e., responses to the item "How important is God in your life") throughout Waves 3-6 of the WVS (1995-2014). We indexed secularization via both participation and identification, which researchers have used as secularization proxies in past work [22]. In total, 44 nations (218,603 individuals) had data on moralizing religious beliefs and religiosity for at least two waves from 1995-2014. 
Our central hypothesis was that nations higher in moralizing religious beliefs in the first 3 WVS waves would lose religion the slowest throughout the next 3 WVS waves, even controlling for differences in non-moralizing religious beliefs (belief in the afterlife, the soul, God, and heaven), wealth, and inequality. To avoid confounding moralizing beliefs with Christianity, we also controlled for the prevalence of Christianity (percent of believers who identified as Christian) in our analyses. Table 1 lists all countries in terms of key variables. The "Methods and Materials" section contains more information about all measures in this study. We tested our hypothesis using multi-level modeling with intercepts and slopes varying randomly across nations to account for the nested structure of the data.

Table 1.

Study 1 Sample Characteristics.

\begin{tabular}{|c|c|c|c|c|c|c|}
\hline Nation & Subjects & $\begin{array}{c}\text { Moralizing } \\
\text { Beliefs } \\
\end{array}$ & $\begin{array}{c}\text { Non-Moralizing } \\
\text { Beliefs } \\
\end{array}$ & $\begin{array}{c}\% \\
\text { Christian } \\
\end{array}$ & $\begin{array}{c}\text { GDP Per } \\
\text { Capita } \\
\end{array}$ & GINI \\
\hline Pakistan & 3933 & 100 & 100 & 1.6 & 654 & 28.7 \\
\hline Philippines & 3600 & 94.47 & 97.15 & 85.0 & 1200.4 & 46 \\
\hline Bangladesh & 3025 & 93.61 & 87.76 & 0.2 & 383.1 & 32.9 \\
\hline Turkey & 9289 & 85.75 & 89.96 & 0.4 & 3877.1 & 41.3 \\
\hline Puerto Rico & 1884 & 82.63 & 91.54 & 96.7 & 11667.6 & 56 \\
\hline United States & 6223 & 80.09 & 89.19 & 78.3 & 28671.5 & 40.2 \\
\hline Nigeria & 6778 & 77.98 & 93.90 & 49.3 & 1273.3 & 51.9 \\
\hline Romania & 4518 & 76.14 & 83.56 & 99.5 & 1573.1 & 28.2 \\
\hline Peru & 5422 & 75.58 & 86.97 & 93 & 2179.2 & 53.7 \\
\hline Venezuela & 2400 & 68.74 & 84.91 & 89.3 & 3559.8 & 47.8 \\
\hline Georgia & 4710 & 67.91 & 72.35 & 88.5 & 669.8 & 37.1 \\
\hline South Africa & 16786 & 67.28 & 89.47 & 81.2 & 3752.4 & 32 \\
\hline Chile & 5700 & 63.41 & 82.02 & 89.4 & 5117.7 & 54.9 \\
\hline Mexico & 10827 & 61.49 & 77.94 & 95.1 & 3810.9 & 48.2 \\
\hline Azerbaijan & 3004 & 60.52 & 71.00 & 3.0 & 316.2 & 34.7 \\
\hline Taiwan & 3245 & 58.31 & 68.96 & 5.5 & 13076 & 33.8 \\
\hline Moldova & 3038 & 57.94 & 65.87 & 97.4 & 470.1 & 36.9 \\
\hline Colombia & 10562 & 55.49 & 84.40 & 92.5 & 2939.1 & 56.9 \\
\hline Brazil & 4768 & 54.7 & 82.80 & 95.9 & 4950.7 & 59.6 \\
\hline Macedonia & 2050 & 53.92 & 62.08 & 59.3 & 2387.2 & 42.8 \\
\hline Ukraine & 5311 & 53.75 & 58.07 & 83.8 & 752.3 & 39.3 \\
\hline Argentina & 6398 & 53.01 & 75.34 & 85.2 & 8053.1 & 48.9 \\
\hline Australia & 6174 & 52.53 & 72.07 & 67.3 & 20868.1 & 32.6 \\
\hline Finland & 3004 & 52.23 & 71.91 & 81.6 & 26349.4 & 27.7 \\
\hline South Korea & 7070 & 51.01 & 59.66 & 29.4 & 12332.9 & 31.7 \\
\hline India & 10124 & 49.61 & 65.64 & 2.5 & 391.2 & 31.7 \\
\hline New Zealand & 2996 & 47.95 & 73.81 & 57.0 & 16784.1 & 36.2 \\
\hline Armenia & 3100 & 47.36 & 57.02 & 98.5 & 399.6 & 36.2 \\
\hline Albania & 1999 & 46.86 & 54.20 & 35.0 & 904 & 27 \\
\hline Belarus & 4642 & 44.62 & 50.96 & 86.2 & 1000.2 & 32 \\
\hline Spain & 6319 & 42.92 & 68.15 & 78.6 & 15437.4 & 31.8 \\
\hline Switzerland & 3853 & 38.09 & 69.35 & 81.3 & 48833.7 & 33.9 \\
\hline
\end{tabular}




\begin{tabular}{lcccccc} 
Slovenia & 3113 & 37.8 & 52.06 & 78.4 & 10708.6 & 29.2 \\
Russia & 8534 & 36.9 & 42.43 & 73.3 & 2263.5 & 46.1 \\
Uruguay & 3000 & 34.83 & 60.62 & 57.9 & 6601.5 & 45.9 \\
Bulgaria & 2073 & 33.74 & 42.40 & 82.1 & 1511.5 & 30.7 \\
Estonia & 2554 & 33.25 & 41.12 & 39.9 & 2642.9 & 39.5 \\
Norway & 2152 & 31.02 & 55.59 & 84.7 & 34789.5 & 27.6 \\
Montenegro & 1300 & 28.67 & 38.30 & 71.0 & 1577.1 & 30.2 \\
Serbia & 2480 & 27.56 & 39.70 & 92.5 & 2925.9 & 32 \\
Hungary & 3121 & 26.34 & 41.87 & 81.0 & 4490.6 & 27.9 \\
Japan & 8170 & 25.45 & 56.34 & 1.6 & 43441.3 & 32.1 \\
Germany & 6136 & 21.96 & 48.68 & 68.7 & 31901.3 & 29 \\
Sweden & 3218 & 21.1 & 52.68 & 76.2 & 29911.8 & 25.3 \\
\hline
\end{tabular}

Note. GDP per capita is in 1995 dollars. "Moralizing Beliefs" and "Non-Moralizing Beliefs" represent the percent of people, on average, who hold three moralizing religious beliefs (hell, the Devil, \& sin) and four non-moralizing religious beliefs (the afterlife, the soul, heaven, God), respectively.

Does the perception that religion is necessary for morality predict secularization? We tested this question with a regression containing the interaction between wave and moralizing beliefs, controlling for the interaction between wave and non-moralizing beliefs and all associated main effects. This model revealed that, on average, countries exhibited no significant change in their religiosity over time, $b=.03, \beta=.02, S E=.03, t=.80, p=.43$. However, the interactions revealed variation across countries that was linked to both moralizing and nonmoralizing beliefs. Countries that highly endorsed moralizing beliefs before 1995 such as Mexico and Romania grew more religious from 1995 from 2014, $b=.88, \beta=.15, S E=.37, t=$ $2.40, p=.02$, whereas countries that highly endorsed non-moralizing religious beliefs before 1995 grew less religious from $1995-2014, b=-1.56, \beta=-.22, \mathrm{SE}=.43, t=-3.59, p=.001$. We did not predict the latter of these effects, but it is unsurprising since nations that higher in religiosity at the start of our analysis time frame had more potential people who could deconvert throughout our timeframe.

Next, we re-ran this model controlling for our key co-variates: GDP per capita, GINI, and prevalence of Christianity. Each key result replicated. Moralizing beliefs still predicted increases in religiosity, and non-moralizing beliefs predicted decreases in religiosity (see Table 2 for all statistics). In sum, the countries in this study with weaker moralizing beliefs in Waves 1-3 were more likely to lose religion across Waves 3-6 than countries with stronger moralizing beliefs (see Figure 1). This model explained $86 \%$ of the culture-level variation in secularization from 1995 until 2014. Lastly, to control for the interdependence between countries, we re-ran our initial model controlling for geographic region. Once again, each of our key results replicated. The full results of this model are presented in Table S1 of our SM. 


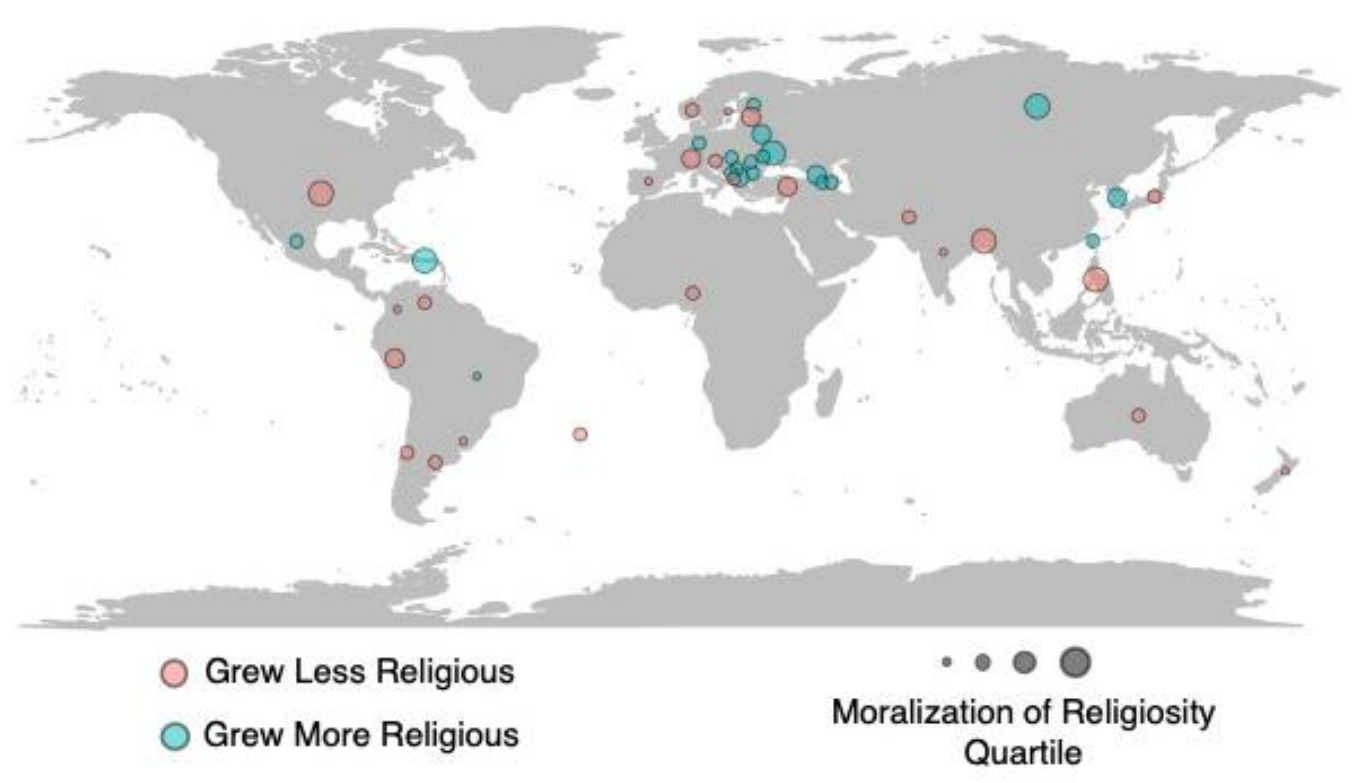

Figure 1. The sample of countries in Study 1. Each data point represents a country. Data points for countries that became less religious are red, and data points for countries that grew more religious are blue. The size of each country's data point corresponds to its moralization of religiosity quartile, such that larger data points reflect greater endorsement of moralizing religious beliefs, controlling for non-moralizing religious beliefs.

Table 2.

Summary of Multiple Regression Analyses for Variables Predicting Religious Change.

\begin{tabular}{|c|c|c|c|c|c|c|}
\hline & Nations & $R_{\text {level-2 }}^{2}$ & $b(\mathrm{SE})$ & $\beta$ & $t$ & $p$ \\
\hline Model 1 & 49 & .86 & & & & \\
\hline Moralizing Beliefs & & & $1.52(1.41)$ & .22 & 1.08 & .29 \\
\hline Non-Moralizing Beliefs & & & $4.00(1.68)$ & .48 & 2.39 & .02 \\
\hline Wave & & & $.016(.033)$ & .01 & .49 & .63 \\
\hline Gini & & & $.025(.012)$ & .18 & 2.02 & .05 \\
\hline GDP per capita & & & $-.0003(.0001)$ & -.28 & -3.10 & .004 \\
\hline$\%$ Christian & & & $-.002(.003)$ & -.05 & -.70 & .49 \\
\hline Wave * Moralizing Beliefs & & & $1.91(.53)$ & .21 & 2.24 & .03 \\
\hline Wave * Non-Moralizing Beliefs & & & $-2.04(.64)$ & -.30 & -3.22 & .003 \\
\hline Wave * Gini & & & $.006(.005)$ & .05 & 1.14 & .26 \\
\hline Wave * GDP per capita & & & $1.18 \mathrm{e}-6(4.00 \mathrm{e}-6)$ & .01 & .29 & .77 \\
\hline Wave * \% Christian & & & $.003(.001)$ & .07 & 2.55 & .02 \\
\hline
\end{tabular}

Note. All predictor variables were centered before analysis. $R^{2}$ represents the percentage of country-level variation explained.

These results demonstrate that cross-cultural differences in the moralization of religiosity can explain why some nations have secularized faster than others. Countries high in moralization 
of religiosity were less likely to secularize, whereas countries high in non-moralizing religious beliefs were more likely to secularize over time. Nevertheless, cross-cultural findings do not always represent individual-level change, a phenomenon known as the ecological fallacy [23]. Therefore, we next tested whether the moralization of religiosity could explain why some individuals abandon faith over time while others maintain it.

\section{Study 2: Moralization of Religiosity and Religious Belief Across the Lifespan}

Why do some people remain religious throughout their lives, while others deconvert? Research in both the psychology and sociology of religion suggests that childhood socialization is a robust predictor of religious belief later in life [24-27]. For example, childhood exposure to credibility-enhancing displays (CREDs) — costly behaviors that signify authenticity of belief to observers - has been shown to increase the likelihood that individuals will adopt and maintain religious belief [28-30]. Similarly, we suggest that people who grew up in households that strongly moralized religion are more likely to stay religious across the lifespan. Study 2 employed a retrospective-longitudinal design to test this prediction.

We recruited 701 Americans ages 40 and older who grew up in a religious household. Participants estimated how important religion was in their childhood household (household religiosity), how strongly their family or caretakers perceived religion to be essential to morality (household moralization of religiosity), and the extent to which they currently believed that religion was essential to morality (participant moralization of religiosity), in addition to completing a measure of exposure to CREDs [26]. For each decade of their life through ages 4150 , participants also and reported how important religion was to them (participant religiosity) and their perceptions of their moral reputation.

We hypothesized that household moralization of religiosity would predict changes in the strength of participants' religiosity across the lifespan, even controlling for household religiosity. We also explored whether reputational concerns impact the relationship between moralization of religiosity and maintenance of religious belief. Specifically, we hypothesized that religiosity would be positively associated with participants' perceptions of their moral reputation over time, especially for participants who strongly moralize religion.

We ran a series of multilevel models to test our hypotheses. First, we assessed what household characteristics best predicted religiosity across the lifespan with a random intercepts and slopes model. This model included household moralization of religiosity, household religiosity, exposure to CREDs, gender, age, education, and income interacted with the linear and quadratic effects of time. The results of this analysis revealed that household moralization of religiosity positively moderated the linear slope, $b=.05, \beta=.07, S E=.02, t=3.25, p=.001$ of participant religiosity. Probing this interaction further revealed that people who reported low household moralization of religiosity linearly lost religion over time, $b=-.19, \beta=-.14, S E=.04$, $t=-4.79, p<.005$, whereas people who reported high household moralization of religiosity showed no loss of religion, $b=.01, \beta=.01, S E=.04, t=.25, p=.80$ (see Figure 2).

Conversely, household religiosity negatively moderated the linear slope of participant religiosity, $b=-.11, \beta=-.14, S E=.03, t=-3.97, p<.001$, such that people who grew up in households with low religiosity became marginally more religious over time, $b=.10, \beta=.07$, $S E=.05, t=1.85, p=.07$, and people who grew up in highly religious households grew less religious over time, $b=-.28, \beta=-.20, S E=.05, t=-5.19, p<.001$. This conceptually replicates our finding from Study 1 that general religiosity predicts greater loss of religion, likely because people with higher religiosity early in life have a greater potential to lose faith over time. All 
other interactions were nonsignificant except for the interaction between gender and the linear slope of participant religiosity, $b=.12, \beta=.15, S E=.05, t=2.40, p=.02$. Results of the full model are presented in Table S2 of our SM.

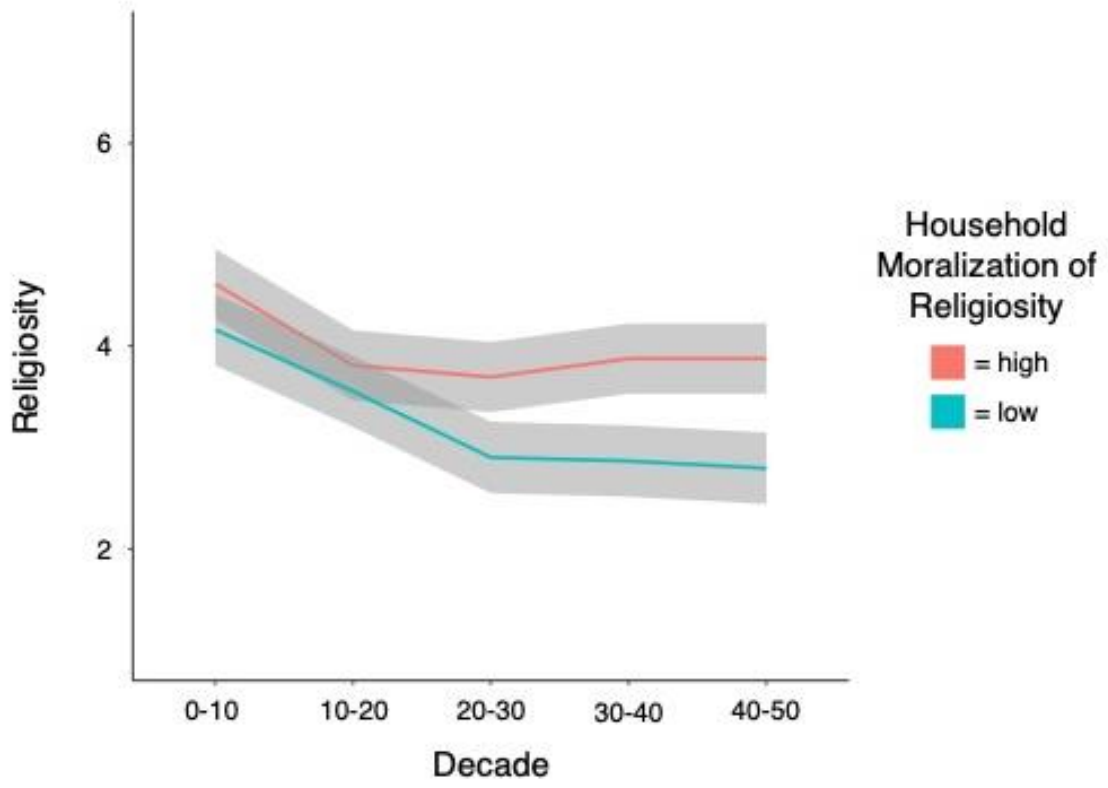

Figure 2. The impact of household moralization of religiosity on religiosity over each decade of the lifespan. Participants who reported household moralization of religiosity one standard deviation above or below the mean are categorized as "high" or "low" in household moralization of religiosity, respectively. Adjusted for household religiosity.

Finally, we tested whether participant religiosity positively predicted perceptions of moral reputation at each decade of participants' lives. A multi-level regression revealed that participant religiosity tracked participants' self-reported moral reputation at each decade, $b=.27$, $\beta=.37, S E=.02, t=23.76, p<.001$. Another regression revealed that this relationship was moderated by participant moralization of religiosity, $b=.04, \beta=.10, S E=.01, t=6.13, p<.001$, and household moralization of religiosity, $b=.02, \beta=.06, S E=.01, t=3.69, p<.001$. Probing these interactions revealed that participant religiosity more strongly predicted moral reputation at each decade for people who also strongly moralized religion, $b=.36, \beta=.50, S E=.03, t=$ $19.62, p<.005$, and for people whose family strongly moralized religion, $b=.33, \beta=.46, S E=$ $.02, t=20.87, p<.005$. The full results of this model is presented in Table S3 of our SM.

Our findings demonstrate that the extent to which individuals are socialized to believe that religion is necessary for morality predicts a stronger likelihood to maintain religion across the lifespan. These results also suggest that the moralization of religiosity might encourage people to maintain religious belief because of the perceived reputational costs of deconverting, a prediction we address more explicitly in our final study. Next, we assessed the extent to which the moralization of religiosity uniquely predicts attitudes toward loss of religion. 


\section{Study 3: Individual-Level Variation in Religious Guilt and Anti-Atheism Prejudice}

Our first two studies provided evidence that past differences in the moralization of religiosity can explain variation in current religiosity. In Studies 3a-3c, we tested whether individuals' present-day moralization of religion can predict their likelihood of deconverting in the future. Religious participants $\left(N_{3 a}=299 ; N_{3 b}=300 ; N_{3 c}=325\right)$ rated how guilty they would feel after abandoning different religious practices and how strongly they believed that religion was essential to morality. To test whether the moralization of religiosity uniquely predicted guilt over deconverting, we also had participants in each study complete a different battery of control measures that prior research has linked to religiosity, including conservatism [31], death anxiety [17], loneliness [18], lack of control [19], exposure to CREDs and childhood service attendance [30], and mind-body dualism [32]. We predicted that people who moralize religion would anticipate more guilt over no longer engaging in religious practices. We also predicted that people who moralize religion should be more prejudiced towards atheists.

First, we examined whether moralization of religiosity predicted greater anticipated guilt over deconverting. As predicted, moralization of religiosity was positively correlated with religious guilt in Studies 3a, $r=.57, p<.001,3 \mathrm{~b}, r=.57, p<.001$, and $3 \mathrm{c} r=.47, p<.001$. A series of multiple regressions found that moralization of religiosity significantly predicted religious guilt above and beyond religiosity and conservatism in all three studies. This relationship held when controlling for death anxiety, loneliness, and perceived personal control in Study 3b, and when controlling for dualist beliefs, exposure to CREDs, and childhood service attendance in Study 3c (see Table 3).

Table 3.

Summary of Multiple Regression Analyses for Variables Predicting Religious Guilt.

\begin{tabular}{|c|c|c|c|c|c|c|}
\hline & $d f$ & Adj. $R^{2}$ & $b(\mathrm{SE})$ & $\beta$ & $t$ & $p$ \\
\hline Model 1: Study 3a & 295 & .37 & & & & \\
\hline Moralization of Religiosity & & & $.56(.07)$ & 46 & 8.40 & $<.001$ \\
\hline Conservatism & & & $.02(.04)$ & .02 & .45 & .65 \\
\hline Religiosity & & & $.29(.07)$ & .23 & 4.51 & $<.001$ \\
\hline Model 2: Study 3b & 293 & .37 & & & & \\
\hline Moralization of Religiosity & & & $.58(.07)$ & 47 & 8.80 & $<.001$ \\
\hline Conservatism & & & $.03(.04)$ & .04 & .85 & .40 \\
\hline Religiosity & & & $.30(.06)$ & .25 & 4.85 & $<.001$ \\
\hline Death Anxiety & & & $-.13(.20)$ & -.03 & -.66 & .51 \\
\hline Loneliness & & & $-.01(.14)$ & -.002 & -.04 & .97 \\
\hline Personal Control & & & $.03(.06)$ & .03 & .52 & .60 \\
\hline Model 3: Study 3c & 318 & .25 & & & & \\
\hline Moralization of Religiosity & & & $.44(.06)$ & .38 & 7.07 & $<.001$ \\
\hline Conservatism & & & $.03(.03)$ & .04 & .83 & .40 \\
\hline Religiosity & & & .16(.07) & .13 & 2.28 & .02 \\
\hline Exposure to CREDs & & & $.16(.07)$ & .14 & 2.13 & .03 \\
\hline Childhood Service Attendance & & & $-.01(.01)$ & -.05 & -.76 & .45 \\
\hline Dualism & & & $.03(.06)$ & .03 & .47 & .64 \\
\hline
\end{tabular}


Note. All predictor variables are indented below the study model.

Next, we analyzed the relationship between moralization of religiosity and anti-atheism prejudice. moralization of religiosity was positively associated with anti-atheism prejudice in Studies 3a, $r=.81, p<.001,3 \mathrm{~b}, r=.72, p<.001$, and $3 \mathrm{c}, r=.69, p<.001$. A second set of multiple regressions revealed that moralization of religiosity significantly predicted anti-atheism prejudice above and beyond religiosity and conservatism in all three studies. This relationship held when controlling for death anxiety, loneliness, and perceived personal control in Study $3 b$, and when controlling for dualist beliefs, exposure to credibility-enhancing CREDs, and childhood service attendance in Study 3c (see Table 4).

Table 4.

Summary of Multiple Regression Analyses for Variables Predicting Anti-Atheism Bias.

\begin{tabular}{|c|c|c|c|c|c|c|}
\hline & $d f$ & Adj. $R^{2}$ & $b(\mathrm{SE})$ & $\beta$ & $t$ & $p$ \\
\hline Model 1: Study 2a & 295 & .66 & & & & \\
\hline Moralization of Religiosity & & & $.67(.04)$ & .67 & 16.58 & $<.001$ \\
\hline Conservatism & & & $.10(.03)$ & .15 & 3.40 & $<.001$ \\
\hline Religiosity & & & $.18(.04)$ & .17 & 4.25 & $<.001$ \\
\hline Model 2: Study 2b & 293 & .60 & & & & \\
\hline Moralization of Religiosity & & & $.57(.04)$ & .59 & 14.01 & $<.001$ \\
\hline Conservatism & & & $.15(.02)$ & .25 & 6.45 & $<.001$ \\
\hline Religiosity & & & $.14(.04)$ & .15 & 3.77 & $<.001$ \\
\hline Death Anxiety & & & $-.22(.12)$ & -.07 & -1.79 & .07 \\
\hline Loneliness & & & $-.04(.09)$ & -.02 & -.51 & .61 \\
\hline Personal Control & & & $.01(.04)$ & .01 & .21 & .83 \\
\hline Model 3: Study 2c & 318 & .56 & & & & \\
\hline Moralization of Religiosity & & & $.53(.04)$ & .56 & 13.63 & $<.001$ \\
\hline Conservatism & & & $.16(.02)$ & .27 & 7.04 & $<.001$ \\
\hline Religiosity & & & $.17(.04)$ & .17 & 3.83 & $<.001$ \\
\hline Exposure to CREDs & & & $-.02(.05)$ & -.02 & -.34 & .73 \\
\hline Childhood Service Attendance & & & $.003(.01)$ & .02 & .38 & .71 \\
\hline Dualism & & & $-.01(.04)$ & -.01 & -.35 & .72 \\
\hline
\end{tabular}

Note. All predictor variables are indented below the study model.

These results indicate a robust relationship between moralization of religiosity, guilt over deconverting, and anti-atheism prejudice that cannot be accounted for by other social and psychological forces associated with religiosity. This suggests that people may be more motivated to keep their faith - and more likely to denigrate the faithless - if they believe that religion is necessary to be a good person. In our next study, we further examined how the moralization of religiosity affects attitudes toward nonbelievers. 


\section{Study 4: Moralization of Religiosity and Attitudes Towards Deconverts}

Our studies suggest that people who moralize religion perceive a reputational cost to abandoning religion that may contribute to their unwillingness to deconvert. But are these people's intuitions correct? Study 4 examined this question by testing whether the moralization of religiosity could predict negative attitudes toward deconverts. Five hundred and thirteen religious Americans participated in this study. Participants reported their religiosity and the extent to which they perceived religion as essential to morality and completed two tasks designed to measure attitudes toward deconverts.

We measured implicit moral distrust using a conjunction fallacy task [12], which assesses whether people implicitly view an immoral behavior - in this case, serial murder - as more representative of a specific group of people than the general public - a logical impossibility. We predicted that people high in moralization of religiosity would be more likely to commit the conjunction fallacy against deconverts and atheists than against religious believers. Next, we measured explicit bias toward deconverts using a social distance task [33]. Participants rated how willing they would be to interact with a target at different levels of social proximity (e.g., "As close relatives by marriage," "As neighbors on the same street," "As citizens in my country," etc.) We predicted that people high in moralization of religiosity would demonstrate a greater desire for social distance from a deconvert target than from targets who maintained the same level of religiosity or became more religious.

We tested our hypotheses with a series of multiple regressions. First, we tested whether moralization of religiosity predicted higher rates of conjunction fallacy errors in the deconvert vs. religious and the atheist vs. religious target conditions. Moralization of religiosity predicted higher error rates for the atheist target, $b=.10, \beta=.45, S E=.03, t=3.03, p<.005$, and deconvert target, $b=.10, \beta=.45, S E=.04, t=2.90, p<.005$, versus the religious target above and beyond general religiosity, conservatism, SES, income, education, age, and gender. The full results of this model are presented in Table S4 in the SM.

Next, we examined whether moralization of religiosity predicted greater social distance from the deconvert target and found that moralization of religiosity positively predicted deconvert social distance, $b=6.06, \beta=.42, S E=.66, t=9.18, p<.001$, when controlling for religiosity and the other sample demographics listed above. People higher in moralization of religiosity also distanced themselves further from the deconvert than the target who maintained the same level of religiosity, $b=3.27, \beta=.28, S E=.56, t=5.89, p<.001$, and the target that became more religious, $b=3.67, \beta=.30, S E=.57, t=6.49, p<.001$. The full results of these models are presented in Table S5-S7 in the SM.

These results indicate that the moralization of religiosity may motivate people to stay religious because it also encourages negative attitudes towards people who have abandoned religion. Moralization of religiosity predicted higher rates of conjunction fallacy errors against deconverts, as well as a desire for greater social distance from people who have deconverted. People high in moralization of religiosity were also more likely to commit the conjunction fallacy against atheists, extending our findings from Study 3 and suggesting that the moralization of religiosity encourages ani-atheist prejudice. Taken together, this indicates that the moralization of religiosity may encourage people to maintain their faith for fear of the reputational costs associated with being nonreligious. 


\section{Study 5: Testing the Causality of Moralization of Religiosity}

Studies 1-4 suggest that moralization of religiosity motivates people to stay religious and shun nonbelievers. In our final study, we test the causal nature of this relationship in a controlled experiment. Four hundred and sixty-one Americans participants were randomly assigned to an experimental $(n=253)$ or control $(n=208)$ condition. All participants read a vignette that asked them to imagine that they were a member of a community where nearly everyone was religious, and everyone felt that religion was important. Participants in the experimental condition read that their community believes that being religious is necessary to be a good person, whereas those in the control condition read that their community believes that religion is important but not necessary to be moral. Participants then responded to our outcome measures as if they were a member of their assigned community. We predicted that participants primed with moralization of religiosity would anticipate more religious guilt, be less willing to express doubts about their faith, and show more prejudice against deconverts than those in the control condition.

We tested our hypotheses with a series of multiple regressions. First, we tested whether our vignettes successfully manipulated perceptions of each community's moralization of religiosity. Participants in the experimental condition believed that their fictional community moralized religion to a greater extent than those in the control condition, $b=1.56, \beta=.35$, $S E=.19, t=8.13, p<.001$. Next, we examined the effects of condition on our main variables of interest. Participants in the experimental condition anticipated more guilt over deconverting, $b=.92, \beta=.21, S E=.20, t=4.54, p<.001$, were less willing to express doubts about their faith, $b=-1.32, \beta=-.35, S E=.16, t=-8.04, p<.001$, and were more prejudiced against deconverts, $b=.92, \beta=.30, S E=.14, t=6.61, p<.001$. The effect of condition was significant for both religious and nonreligious participants across all key outcome measures (see Model 1 in Tables S8-S10 in the SM). See Figure 3 for a visualization of these effects.
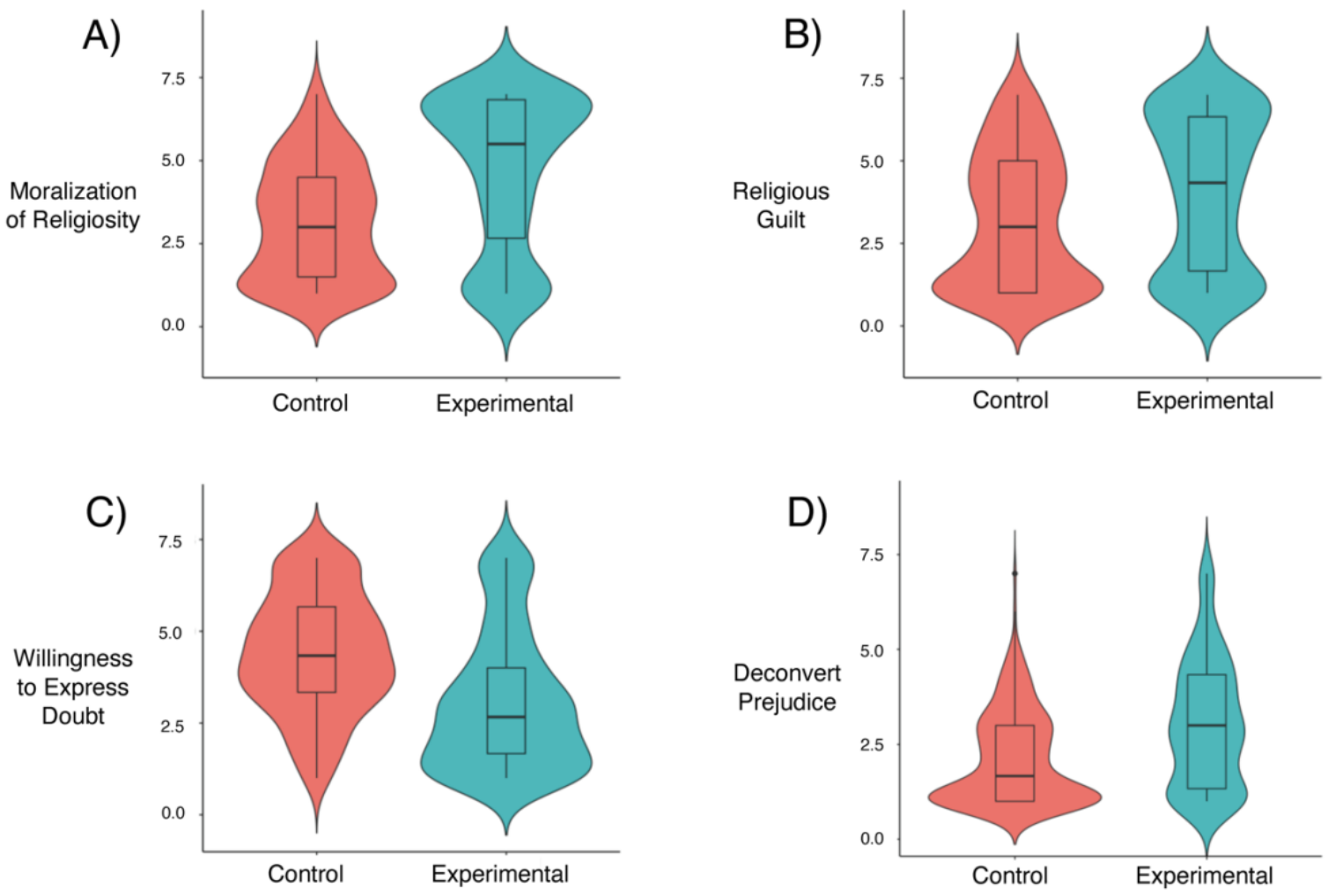
Figure 3. Violin plots displaying the differences between the moralization and control conditions on key outcome variables in Study 5. Compared to those in the control condition (red), participants in the experimental condition (blue) anticipated more guilt after deconverting, less willingness to express doubt about their faith, and a higher likelihood of expressing prejudice against people who deconverted.

Finally, we ran a series of exploratory analyses to test whether these effects replicated when controlling for perceived warmth and religiosity of the community, and reactance against community norms. All of our key results replicated; condition still predicted religious guilt, $b=.38, \beta=.08, S E=.16, t=2.41, p=.02$, willingness to express doubts, $b=-.93, \beta=-.25$, $S E=.17, t=-5.60, p<.001$, and prejudice against deconverts, $b=.60, \beta=.19, S E=.13$, $t=4.43, p<.001$. Condition was a relatively weaker predictor of religious guilt than of our other two variables of interest in these models, suggesting that group-level moralization of religiosity has a more robust impact on public behaviors like expressing doubts about one's religion and associating with nonbelievers than on the private experience of religious guilt (see Model 2 in Tables S8-S10 in the SM for results of the full analyses).

This study provides experimental support for the effects of moralization of religiosity on religious adherence and prejudice against nonbelievers. Participants who imagined themselves in a community that strongly moralized religious belief anticipated more guilt over abandoning religion, were less willing to express potential doubts to other community members, and showed greater bias against deconverts. These effects replicated in exploratory analyses controlling for community warmth, community religiosity, and reactance against community norms. These results indicate that moralization of religiosity motivates people to continue participating in religion, even when they privately feel doubt.

\section{General Discussion}

Religion has influenced culture and human behavior for millennia, but this is beginning to change. The loss of religion within and across nations has enormous implications, yet we still do not fully understand why some people and groups lose religion while others do not. Past research on the spread of prosocial religions shows how punitive religious beliefs served a crucial role in the emergence of large-scale cooperative societies [3-7]. However, we suggest that the moralization of religious belief itself uniquely explains global variation in current-day religiosity.

We identify the moralization of religiosity as a critical psychological mechanism that explains the loss of religion across individuals and societies. Across five studies, we provide evidence that the moralization of religiosity inhibits nation-level secularization and person-level deconversion. Our multi-method studies show that the moralization of religiosity predicts changes in national levels of religiosity (Study 1) and individual religiosity across the lifespan (Study 2), as well as individual likelihood to deconvert in the future (Studies 3 and 5). Furthermore, we demonstrate how moral reputation concerns play a role in this relationship. Religiosity is positively associated with self-reported moral standing over time, particularly among people who strongly moralize religion (Study 2), and moralization of religiosity predicts more implicit bias and social distance from nonbelievers (Studies 4 and 5).

We also find that the moralization of religiosity may motivate negative attitudes toward atheists [see 13]. Moralization of religiosity predicted greater anti-atheism prejudice above and 
beyond general religiosity, conservatism, and a host of other measures (Study 3). People high in moralization of religiosity were also more likely to intuitively see atheists as more immoral than religious believers (Study 4). These findings build upon previous research indicating that bias towards atheists stems from moral distrust [12-14] by showing that anti-atheist prejudice stems from the belief that religion is necessary to be moral. As the number of nonreligious people worldwide surges, this line of research will have critical implications for interpersonal and intergroup contact. Individuals and nations that strongly moralize religion may be most likely to denigrate those who are not religious. Future research should therefore focus more intently on how differences in the moralization of religiosity may impact relationships between religious and nonreligious individuals and societies.

Despite the strength of our findings, the current research has limitations. First, we did not directly manipulate participants' moralization of religiosity because previous work has questioned whether researchers can reliably manipulate people's religious beliefs in a laboratory setting [34-36]. However, our final study bypasses these concerns by demonstrating that manipulating the moralization of religiosity in one's community can impact people's anticipated religious behaviors. Another limitation of the current research is that most of our studies used American participants, but our findings from Study 1 suggest that the moralization of religiosity can explain the loss of religion across nations. We encourage future research on the cross-cultural facilitators of secularization and deconversion, particularly in non-WEIRD (Western, Educated, Industrialized, Rich, and Democratic) cultures.

Rather than focusing on the properties of individual people or groups that lead to secularization, we show that the nature of religious belief is key to understanding patterns of religious change across individuals and societies. Our studies show that viewing religion as necessary to morality is a key inhibitor of secularization around the globe, and of deconversion across the lifespan. Whether or not we need God to be good is up for debate, but our beliefs about religion's necessity for morality can give us powerful insight into the future of worldwide religiosity.

\section{Materials and Methods}

We preregistered our hypotheses and study characteristics for Studies 3-5 and have hosted our data, stimuli, and analysis code for all studies at https://osf.io/9jirkg/. We did not preregister Study 1 because crucial parameters in our analysis required closely examining the WVS data. For example, we could not determine the sample size of our study until examining how many nations have data on our key variables. Conversely, we could not finalize our measures of moralization of religiosity and secularization until examining which variables afforded a sufficient number of individuals and cultures for adequately powered analysis. Similarly, we did not preregister our analysis plan for Study 2 because of the nature of our retrospective dataset. Longitudinal data can be difficult to fit with a model, and we could not anticipate the best-fitting modeling approach in advance.

\section{Study 1}

Sample. Across all waves, the WVS contains data on 341,271 individuals across 100 nations. However, not all countries are sampled in each WVS wave, and not all nations received the same questions, which means that our analyses contained subsets of the total sample. In total, 52 nations had data on moralization of religiosity, and 44 of these nations $(218,603$ individuals) also included religiosity data for at least two waves from 1998-2014. We tested our hypotheses 
using these 44 nations. Table 1 contains the sample characteristics of each country in this final sample.

We chose to measure moralization of religiosity using waves 1-3 and secularization using waves 3-6 because this afforded us a balance between achieving an adequately powered sample size of cultures and testing for secularization over a sufficiently long period. For example, if we had only measured moralization of religiosity over the first 2 WVS waves, we would only have been able to analyze 21 nations. In contrast, if we had measured moralization of religiosity over the first 4 WVS waves, we would only have three waves to measure secularization, and our statistical models would not have converged.

Measures. To measure moralization of religiosity and general religiosity, we needed items that (a) were frequently asked in early waves of the WVS, and (b) captured both moralizing and non-moralizing beliefs. We selected a question that appeared in the first three waves of the WVS, and which required participants to indicate which of 7 beliefs they held (God, the Devil, the afterlife, the soul, heaven, hell, sin). Of these beliefs, previous work has used 3 (the Devil, hell, sin) to measure moralizing religious beliefs and one other (heaven) to measure non-moralizing religious beliefs [37-38]. We included three additional beliefs that did not signal moralization (God, the afterlife, the soul) in our measure of non-moralizing religious beliefs. In a varimax exploratory factor analysis with a 2-factor solution, non-moralizing beliefs all loaded above .60 on one factor, and moralizing beliefs loaded above .60 on another, with no cross-loadings. We therefore created separate moralizing and non-moralizing religious belief indices by averaging together these groups of variables.

This does not mean that moralizing and non-moralizing beliefs are orthogonal, and many people who believe in heaven also believe in hell. Our approach merely presumes that there may be some nuance to people's religious beliefs, and that moralizing and non-moralizing beliefs may not be isomorphic. For example, heaven and hell beliefs correlate with one another across cultures, but they have divergent associations with well-being and crime rates [37].

We captured change in religiosity using change in nation-level endorsement of 2 items included (and formatted identically) in all but the first two WVS waves. For the first item, participants responded to the prompt "Apart from weddings, funerals, and christenings, about how often to you attend religious services these days?" using a 1-7 scale where 1 represented "More than once a week" and 7 represented "Never, practically never." We reverse-scored this item so that higher values represented greater service attendance. For the second item, participants responded to the prompt "How important is God in your life?" using a 1-10 scale where 1 represented "Not important at all" and 10 represented "Very important." Each WVS wave contained other items that measured religious belief, but these two items were consistent in their presence and structure across nations and waves, so they represented ideal items for capturing secularization. These items correlated highly in waves $3(r=.85), 4(r=.71), 5(r=$ $.74)$, and $6(r=.71)$, and so for the sake of parsimony, we averaged both measures into a standardized index for our primary analyses.

We indexed wealth using GDP per capita, which we collected from the International Monetary Fund (IMF). All estimates were from 1995 (the starting year of WVS wave 3), and rates were reported in terms of 1995 USD. The poorest nation in our sample was Azerbaijan (\$316.2), whereas the wealthiest was Japan (\$48833.7). We indexed inequality using GINI coefficients, which we collected from the World Bank. The World Bank did not contain GINI rates in 1995 for all nations. In these cases, we used GINI from the nearest available year. We 
measured the prevalence of Christianity using the US State Department's International Religious Freedom Report, whose statistics are hosted on Wikipedia.

\section{Study 2}

Sample. We recruited 752 American participants from Amazon Mechanical Turk to take part in this study. Sixteen participants failed an attention check, and 35 were excluded for being less than 40 years old, leaving us with a final sample of 701 (274 men, 425 women, 2 other; $M_{\text {age }}$ $=51.97, S D_{\text {age }}=9.18$ ) in our analyses. We required participants to be at least 40 years old so that we could track attitudes toward religion across multiple time points. Participants did not need to identify as religious but had to have been raised in a religious household.

Measures. To assess participants' moralization of religiosity, we developed a measure in which participants rated their agreement with each of a series of 6 statements about the necessity of religious belief for morality (e.g., "I am a good person because I believe in God," "Religious people are more moral than nonreligious people") on a scale from 1 (strongly disagree) to 7 (strongly agree). An exploratory factor analysis with varimax rotation revealed that one factor explained $71 \%$ of the variance (Eigenvalue $=4.53$ ). All other factors explained $<35 \%$ of the variance (Eigenvalues <.41). An internal consistency analysis indicated that this measure had appropriate reliability $(\alpha=.94)$, and removing any single item did not improve this index.

We measured household religiosity by participants' response to a single item ("Generally, how important was religion in the house you grew up in?") on a scale from 1 (not at all important) to 7 (extremely important). We assessed household moralization of religiosity with a modified form of our moralization of religiosity measure that asked participants to rate the extent to which their family would have agreed with each of the six items $(\alpha=.94)$.

To assess exposure to credibility enhancing displays, participants completed a modified form of the CREDs Scale [29], which includes questions about exposure to parents' religious displays when participants were children (e.g., "Overall, to what extent did your caregiver(s) act as good religious role models?") on a scale from 1 (to no extent at all) to 7 (to an extreme extent). This measure consists of 7 items that we averaged together to create one composite score of exposure to CREDs. We removed four of the seven items because they utilized moralizing religious beliefs (e.g., "To what extent did your caregiver(s) avoid harming others because their religion taught them so?"), leaving us with three items in total $(\alpha=.89)$.

Finally, we measured participants' retrospective religiosity and perceived moral reputation at each decade of their lives (ages 0-10, 11-20, 21-30, 31-40, and 41-50). Participants reported how important religion was to them (e.g., "Generally, how important was religion to you when you were under ten years old?") and their perceptions of their moral reputation (e.g., "In general, to what extent did your community think you were a morally upstanding person when you were in your thirties?") at each of these time points on a scale from 1 (not at all) to 7 (extremely so). Items were grouped by measure, such that participants completed the religiosity items in one block and the moral reputation items in a separate block.

Procedure. Participants completed all measures in random order before providing demographic information and exiting the survey.

\section{Study 3}

Sample. In Studies 3a-3c, we advertised for 300 participants on Amazon Mechanical Turk since a power analysis suggested that a sample size of 300 would give us $58 \%$ power to detect a small effect of $f^{2}=.02$ in a multiple regression. After excluding data from participants 
that failed our attention check, we were left with 299 participants $\left(144\right.$ men, 155 women; $M_{\text {age }}=$ 39.54, $\left.S D_{\text {age }}=12.68\right)$ in Study 3a, 300 participants $\left(129\right.$ men, 171 women; $M_{\text {age }}=41.69, S D_{\text {age }}=$ 12.79) in Study 3b, and 325 participants (135 men, 190 women; Mage $=39.31$, SDage $=13.47$ ) in Study 3c.

Measures. All three sub-studies included measures of moralization of religiosity, religious guilt, religiosity, and anti-atheism prejudice. We assessed moralization of religiosity using the measure we created and used in Study $2\left(\alpha_{3 \mathrm{a}}=.88 \alpha_{3 \mathrm{~b}}=.86, \alpha_{3 \mathrm{c}}=.85\right)$. We measured current religiosity using the Supernatural Belief Scale (SBS) [39], a cross-culturally validated measure of religious belief.

As a proxy for willingness to secularize, we created a 3-item measure of religious guilt designed to gauge how guilty participants would feel if they (a) stopped participating in religious services, (b) stopped reading scripture, and (c) stopped praying. Participants responded to these items on a scale from 1 (not at all guilty) to 7 (extremely guilty) or selected N/A (coded as 0) if they did not engage in the religious behavior referenced in the item. The overall measure was appropriately reliable $\left(\alpha_{3 \mathrm{a}}=.81, \alpha_{3 \mathrm{~b}}=.79, \alpha_{3 \mathrm{c}}=.79\right)$.

We measured anti-atheism prejudice with the 7-item Negative Attitudes Toward Atheists Scale (NAAS) [12], in which participants rate their agreement with a series of negative statements about atheists and atheism (e.g., "I would be uncomfortable with an atheist teaching my child," "In times of crisis, I am more inclined to trust people who are religious") on a scale from 1 (strongly disagree) to 7 (strongly agree). Two items were reverse coded before we averaged all items into one composite measure of anti-atheism bias $(\alpha=.87)$.

Study 3 b Measures. Participants in Study $3 b$ completed three additional measures of death anxiety, loneliness, and personal control. The Death Anxiety Questionnaire [40] assessed fear and concern over dying in a series of 15 questions (e.g., "Does the thought of leaving loved ones behind when you die disturb you?" "Are you worried about not knowing what to expect after death?") using a 3 -point scale ( $0=$ not at all, $1=$ somewhat, $2=$ very much $)$. We then calculated death anxiety by averaging all ratings into one composite score $(\alpha=.89)$.

To assess feelings of loneliness, participants responded to the 8-item UCLA Loneliness Scale [41]. Participants indicated how often they experienced the feelings described in each statement (e.g., "There is no one I can turn to," "I feel isolated from others") using a scale from 1 (never) to 4 (always). Two items were reverse-scored before we averaged all items into one overall measure of loneliness $(\alpha=.89)$.

We measured perceived control over one's life with one item [19]: "Some people feel they have completely free choice and control over their lives, while other people feel that what they do has no real effect on what happens to them. How much personal control do you feel you have over what happens to you?" Participants responded using a scale from 1 (none at all) to 10 (a great deal).

Study 3c Measures. Participants in Study 3c completed three additional measures of dualism, exposure to credibility-enhancing displays, and childhood religious service attendance. We measured dualist beliefs with an adapted form of the Dualism Scale [42], which consists of four statements concerning the relationship between the mind and the body (e.g., "The mind and brain are two separate things," "Some part of our consciousness survives after death"). This measure was adapted to exclude any overtly religious words (e.g., "soul," "spiritual"). Participants rated their agreement with each item on a scale from 1 (strongly disagree) to 7 (strongly agree). We averaged all items together to create one composite score of dualist beliefs $(\alpha=.60)$. We removed one item to increase internal reliability $(\alpha=.74)$. 
We used the CREDs scale from Study 2 [29], this time in its unmodified form, to measure exposure to credibility-enhancing displays $(\alpha=.93)$. Because the CREDs scale only assesses exposure to parental displays and not exposure to community displays of religion, we included a 1-item measure of childhood religious service attendance ("How often did you attend religious services when you were 12 years old?") [34] to which participants responded on a scale from 1 (never) to 7 (very often).

Procedure. First, participants in all studies completed measures of moralization of religiosity, religious guilt, and religiosity in random order; then, they completed the NAAS. Participants in Studies $3 b$ and $3 c$ also completed the additional measures specific to each study in random order. Finally, participants completed demographic items, including political conservatism measured on a scale from 1 (very progressive) to 9 (very conservative).

\section{Study 4}

Sample. We advertised for 500 American religious participants on Amazon's Mechanical Turk to obtain at least 150 participants per between-subjects condition. Five hundred and fortyeight participants took part in this study. We excluded 35 participants' data from analyses because they failed our attention check, leaving us with a total sample of 513 participants $(234 \mathrm{men}, 278$ women, 1 other; $M_{\text {age }}=35.16, S D_{\text {age }}=11.16$ ).

Measures. We assessed religiosity with the SBS [39] and moralization of religiosity with the measure we created and used in Studies 2 and 3. We measured implicit moral distrust of deconverts via a conjunction fallacy task [12]. Participants read a vignette about a homicidal man and determined whether it was more likely that a) the man is a teacher, or b) the man is a teacher [and does not believe in God/who used to be religious, but no longer believes in God/and is a religious believer]. We manipulated the stem of option B randomly between subjects. Conjunction fallacy rates (i.e., choosing option B-a logically incorrect answer) between conditions can help us infer indirectly the degree to which people intuitively see a description of a serial murderer as more representative of atheists, deconverts, and religious believers, respectively. For this analysis, we only included participants who indicated they were not familiar with the conjunction fallacy $(n=456)$, leaving us with 148 participants in the atheist target condition, 148 participants in the deconvert target condition, and 160 participants in the religious target condition.

We measured explicit bias toward deconverts using a social distance task. Participants completed items on the Social Distance Intensity Score (iScore) [33] concerning three different targets, presented in random order: 1) someone who has abandoned religion (deconvert target), 2) someone who has stayed religious (religious maintenance target), and 3) someone who has become more religious (more religious target). The Social Distance iScore combines the Bogardus Social Distance Scale [43] with a Likert scale ranging from 1 (strongly agree) to 5 (strongly disagree) to create a more sensitive and fine-grained measure of social distance. The scale is scored utilizing the rank order from the Bogardus scale as a multiplier to the Likert responses for each of the seven items, such that scores on more extreme items are weighted more heavily than scores on less extreme items. The range of the total iScore is 28-140, with higher scores reflecting a stronger desire for social distance from the target.

Procedure. Participants completed the measures of religiosity and moralization of religiosity and the conjunction fallacy and social distance tasks in random order. In the conjunction fallacy task, participants were randomly assigned to either the atheist target condition, the deconvert target condition, or the religious target condition. In the social distance 
task, participants viewed all three targets (deconvert, religious maintenance, more religious) in random order. Lastly, participants indicated whether they were familiar with the conjunction fallacy before providing demographic information and exiting the study.

\section{Study 5}

Sample. We collected data from 502 American participants on Amazon's Mechanical Turk. We excluded 39 participants' data from analyses because they failed our attention check, leaving us with a final sample of 461 participants $\left(231\right.$ men, 227 women, 3 other; $M_{\text {age }}=40.18$, $\left.S D_{\text {age }}=12.80\right)$.

Measures. We assessed participant religiosity by asking participants to provide their religious affiliation and then identifying them as either religious $(n=248)$ or nonreligious $(n=$ 213). We randomly assigned participants to either an experimental $(n=253)$ or control condition $(n=208)$ in which participants read a vignette that asked them to imagine that they were a member of a highly religious community. In the experimental condition, participants read that their community believes being religious is necessary to be a good person. In the control condition, participants read that their community believes religion is important but not necessary to be moral. After reading the vignette, all participants free-responded to a brief prompt asking them to write about what their daily lives and social interactions might look like in this community. Participants responded to all other measures as if they were a member of the community in their assigned vignette.

To measure community moralization of religiosity, we asked participants to rate the extent to which they thought members of their community would agree with each of the 6 statements from the moralization of religiosity measure used in Studies $2-4(\alpha=.97)$. We measured religious guilt with the same measure used in Study $3(\alpha=.97)$.

We measured willingness to express doubts by asking participants to rate their agreement with each of a series of 3 statements (e.g., "If I decided I didn't believe in God, I would keep it secret if I lived in this community") on a scale from 1 (strongly disagree) to 7 (strongly agree). Responses were reverse-scored so that higher scores reflected greater willingness to express doubts $(\alpha=.82)$.

We assessed deconvert prejudice by asking participants to rate their agreement with each of a series of 3 statements about how they would behave toward deconverts in their community (e.g., "I would exclude someone who has deconverted if I lived in this community") on a scale from 1 (strongly disagree) to 7 (strongly agree). One item was reverse-coded before we averaged all items into one overall measure of deconvert prejudice $(\alpha=.75)$.

We assessed community warmth with one item asking participants how they thought people in this community interacted with one another on a scale from 1 (People are very cold and unfriendly to one another) to 7 (People are very warm and friendly to one another). To assess community religiosity, participants rated their agreement with each of a series of 3 statements about their anticipated religiosity (e.g., "I would probably go to church regularly if I lived in this community") on a scale from 1 (strongly disagree) to 7 (strongly agree; $\alpha=.94$ ). We measured reactance by asking participants to rate their agreement with 3 statements about their anticipated reaction to community norms (e.g., I would try to rebel against the group norms if I lived in this community") on a scale from 1 (strongly disagree) to 7 (strongly agree; $\alpha=.94$ ).

Procedure. First, participants were randomly assigned to either the experimental or control condition. After reading their assigned vignette, participants responded to measures of community warmth, community moralization of religiosity, community religiosity, willingness to 
express doubts, religious guilt, deconvert prejudice, and reactance. Finally, participants completed demographic items, including participant religiosity.

\section{References}

1. Gallup. (2020). "Religion." Washington, D.C. https://news.gallup.com/poll/1690/religion.aspx

2. WIN-Gallup International. (2017, November 14). "Religion prevails in the world." https://web.archive.org/web/20171114113506/http://www.wingia.com/web/files/news/37 0/file/370.pdf

3. Johnson, D. (2005). God's punishment and public goods. Human Nature, 16(4), 410-446.

4. Johnson, D. (2016). God is watching you: How the fear of God makes us human. Oxford University Press, USA.

5. Norenzayan, A., \& Shariff, A. F. (2008). The origin and evolution of religious prosociality. Science, 322(5898), 58-62.

6. Norenzayan, A., Shariff, A. F., Gervais, W. M., Willard, A. K., McNamara, R. A., Slingerland, E., \& Henrich, J. (2016). The cultural evolution of prosocial religions. Behavioral and brain sciences, 39.

7. Watts, J., Greenhill, S. J., Atkinson, Q. D., Currie, T. E., Bulbulia, J., \& Gray, R. D. (2015). Broad supernatural punishment but not moralizing high gods precede the evolution of political complexity in Austronesia. Proceedings of the Royal Society B: Biological Sciences, 282(1804), 20142556.

8. Laue, D. M. G. J. H. (2000). Between Eden and Armageddon: the future of world religions, violence, and peacemaking: the future of world religions, violence, and peacemaking. Oxford University Press, USA.

9. Pew Research Center (2020). "The global God divide." Washington, D.C. https://www.pewresearch.org/global/2020/07/20/the-global-god-divide/

10. Vonasch, A. J., Reynolds, T., Winegard, B. M., \& Baumeister, R. F. (2018). Death before dishonor: Incurring costs to protect moral reputation. Social Psychological and Personality Science, 9(5), 604-613.

11. Strohminger, N., \& Nichols, S. (2014). The essential moral self. Cognition, 131(1), 159171.

12. Gervais, W. M., Shariff, A. F., \& Norenzayan, A. (2011). Do you believe in atheists? Distrust is central to anti-atheist prejudice. Journal of personality and social psychology, 101(6), 1189.

13. Gervais, W. M. (2014). Everything is permitted? People intuitively judge immorality as representative of atheists. PloS one, 9(4), e92302.

14. Gervais, W. M., Xygalatas, D., McKay, R. T., Van Elk, M., Buchtel, E. E., Aveyard, M., ... \& Klocová, E. K. (2017). Global evidence of extreme intuitive moral prejudice against atheists. Nature Human Behaviour, 1(8), 0151.

15. Barber, N. (2013). Country Religiosity Declines as Material Security Increases. CrossCultural Research, 47(1), 42-50. https://doi.org/10.1177/1069397112463328

16. Solt, F., Habel, P., \& Grant, J. T. (2011). Economic Inequality, Relative Power, and Religiosity*: Economic Inequality, Relative Power, and Religiosity. Social Science Quarterly, 92(2), 447-465. https://doi.org/10.1111/j.1540-6237.2011.00777.x

17. Jackson, J. C., Jong, J., Bluemke, M., Poulter, P., Morgenroth, L., \& Halberstadt, J. (2018). Testing the causal relationship between religious belief and death anxiety. 
Religion, Brain \& Behavior, 8(1), 57-68.

https://doi.org/10.1080/2153599X.2016.1238842

18. Aydin, N., Fischer, P., \& Frey, D. (2010). Turning to God in the Face of Ostracism: Effects of Social Exclusion on Religiousness. Personality and Social Psychology Bulletin, 36(6), 742-753. https://doi.org/10.1177/0146167210367491

19. Kay, A. C., Gaucher, D., Napier, J. L., Callan, M. J., \& Laurin, K. (2008). God and the government: Testing a compensatory control mechanism for the support of external systems. Journal of Personality and Social Psychology, 95(1), 18-35. https://doi.org/10.1037/0022-3514.95.1.18

20. Hoogeveen, S., Wagenmakers, E. J., Kay, A. C., \& van Elk, M. (2019). Compensatory Control and Belief in God: A Registered Replication Report Across Two Countries.

21. Jong, J., \& Halberstadt, J. (2017). What is the causal relationship between death anxiety and religious belief? Religion, Brain \& Behavior, 7(4), 296-298. https://doi.org/10.1080/2153599X.2016.1249916

22. Wilson, B. (1998). The secularization thesis: Criticisms and rebuttals. Secularization and social integration: Papers in honor of Karel Dobbelaere, 4, 45.

23. Piantadosi, S., Byar, D. P., \& Green, S. B. (1988). The ecological fallacy. American journal of epidemiology, 127(5), 893-904.

24. Baker, J. O. B., \& Smith, B. (2009). None too simple: Examining issues of religious nonbelief and nonbelonging in the United States. Journal for the Scientific Study of Religion, 48(4), 719-733.

25. Beit-Hallahmi, B. (2014). Psychological perspectives on religion and religiosity. Routledge.

26. Dudley, R. L. (1999). Youth religious commitment over time: A longitudinal study of retention. Review of Religious Research, 41 (1), 110-121.

27. Gervais, W. M., \& Najle, M. B. (2015). Learned faith: The influences of evolved cultural learning mechanisms on belief in Gods. Psychology of Religion and Spirituality, 7(4), 327.

28. Henrich, J. (2009). The evolution of costly displays, cooperation and religion: Credibility enhancing displays and their implications for cultural evolution. Evolution and human behavior, 30(4), 244-260.

29. Lanman, J. A., \& Buhrmester, M. D. (2017). Religious actions speak louder than words: Exposure to credibility-enhancing displays predicts theism. Religion, Brain \& Behavior, 7(1), 3-16.

30. Willard, A. K., \& Cingl, L. (2017). Testing theories of secularization and religious belief in the Czech Republic and Slovakia. Evolution and Human Behavior, 38(5), 604-615.

31. Jost, J. T., Nosek, B. A., \& Gosling, S. D. (2008). Ideology: Its resurgence in social, personality, and political psychology. Perspectives on Psychological Science, 3(2), 126136.

32. Willard, A. K., \& Norenzayan, A. (2013). Cognitive biases explain religious belief, paranormal belief, and belief in life's purpose. Cognition, 129(2), 379-391.

33. Mather, D. M., Jones, S. W., \& Moats, S. (2017). Improving upon Bogardus: Creating a More Sensitive and Dynamic Social Distance Scale. Survey Practice, 10(4), 1-9. https://doi.org/10.29115/SP-2017-0026 
34. Gomes, C. M., \& McCullough, M. E. (2015). The effects of implicit religious primes on dictator game allocations: A preregistered replication experiment. Journal of experimental psychology: General, 144(6), e94.

35. Van Elk, M., Matzke, D., Gronau, Q., Guang, M., Vandekerckhove, J., \& Wagenmakers, E. J. (2015). Meta-analyses are no substitute for registered replications: A skeptical perspective on religious priming. Frontiers in psychology, 6, 1365.

36. Verschuere, B., Meijer, E. H., Jim, A., Hoogesteyn, K., Orthey, R., McCarthy, R. J., ... \& Barbosa, F. (2018). Registered replication report on Mazar, Amir, and Ariely (2008). Advances in Methods and Practices in Psychological Science, 1(3), 299-317.

37. Shariff, A. F., \& Rhemtulla, M. (2012). Divergent effects of beliefs in heaven and hell on national crime rates. PloS one, 7(6), e39048.

38. Yilmaz, O., \& Bahçekapili, H. G. (2016). Supernatural and secular monitors promote human cooperation only if they remind of punishment. Evolution and Human Behavior, 37(1), 79-84.

39. Bluemke, M., Jong, J., Grevenstein, D., Mikloušić, I., \& Halberstadt, J. (2016). Measuring Cross-Cultural Supernatural Beliefs with Self- and Peer-Reports. PLOS ONE, 11(10), e0164291. https://doi.org/10.1371/journal.pone.0164291

40. Conte, H. R., \& Weiner, M. B. (1982). Measuring Death Anxiety: Conceptual, Psychometric, and Factor-Analytic Aspects. 11.

41. Hays, R., \& DiMatteo, M. R. (1987). A Short-Form Measure of Loneliness. Journal of Personality Assessment, 51(1), 69-81. https://doi.org/10.1207/s15327752jpa5101_6

42. Demertzi, A., Liew, C., Ledoux, D., Bruno, M.-A., Sharpe, M., Laureys, S., \& Zeman, A. (2009). Dualism Persists in the Science of Mind. Annals of the New York Academy of Sciences, 1157(1), 1-9. https://doi.org/10.1111/j.1749-6632.2008.04117.x

43. Bogardus, E. S. (1927). Race friendliness and social distance. Journal of Applied Sociology, 11, 272-287. 


\section{Study S1}

\section{Supplemental Materials}

In a pilot study, we tested whether participants' endorsement of the moralizing religious beliefs used in the WVS (the Devil, hell, sin) predicted moralization of religiosity. We predicted that participants who held moralizing religious beliefs would also be more likely to believe that religion is necessary for morality, even when controlling for non-moralizing religious beliefs (the afterlife, heaven, the soul, God).

We recruited 252 religious Americans from Amazon Mechanical Turk to take part in this study. One participant was excluded for failing to identify as religious, leaving a final sample of 251 participants (108 men, 139 women, 4 other; $\left.M_{\text {age }}=39.34, S D_{\text {age }}=13.86\right)$. Participants completed measures of moralization of religiosity and religious beliefs in randomized order.

We measured moralization of religiosity using the same measure from Studies 2-4 ( $\alpha=$ .86). Participants rated their agreement with a series of statements endorsing moralizing religious beliefs ("I believe in hell," "I believe in sin," "I believe the devil exists") and non-moralizing religious beliefs ("I believe in life after death," "I believe people have a soul," "I believe in heaven", "I believe in God") on a scale from 1 (strongly disagree) to 7 (strongly agree). Ratings on the first three statements were averaged into one composite score of moralizing religious beliefs $(\alpha=.89)$, and ratings on the last three statements were averaged into one score of nonmoralizing religious beliefs $(\alpha=.86)$.

Do moralizing religious beliefs predict moralization of religiosity? First, we examined the correlations between all three items. Moralization of religiosity was significantly related to both moralizing, $r=.46, p<.001$, and non-moralizing religious beliefs, $r=.35, p<.001$. Additionally, moralizing and non-moralizing religious beliefs were also highly correlated with each other, $r=.70, p<.001$. Next, we ran a multiple regression with moralizing and nonmoralizing religious beliefs as predictors and moralization of religiosity as the dependent variable. This model revealed that moralizing religious beliefs significantly predicted moralization of religiosity, $b=.43, \beta=.42, S E=.08, t=5.36, p<.001$, but non-moralizing religious beliefs did not, $b=.10, \beta=.06, S E=.13, t=.79, p=.43$. These results demonstrate that moralizing religious beliefs predict moralization of religiosity above and beyond nonmoralizing religious beliefs.

\section{Table S1}

Summary of Multiple Regression Analyses for Variables Predicting Religious Change, Controlling for Geographic Region.

\begin{tabular}{|c|c|c|c|c|c|c|}
\hline & Nations & $R^{2}$ level-2 & $b(\mathrm{SE})$ & $\beta$ & $t$ & $p$ \\
\hline Model 2 & 52 & .82 & & & & \\
\hline Moralizing Beliefs & & & $5.32(1.16)$ & .74 & 4.58 & $<.001$ \\
\hline Non-Moralizing Beliefs & & & $-.49(1.53)$ & -.06 & -.32 & .75 \\
\hline Wave & & & $.03(.16)$ & .03 & .19 & .85 \\
\hline North America & & & $1.65(.58)$ & .31 & 2.85 & .01 \\
\hline South America & & & $1.92(.49)$ & .52 & 3.95 & $<.001$ \\
\hline Europe & & & $.96(.48)$ & .34 & 2.00 & .05 \\
\hline Africa & & & $2.44(.62)$ & .39 & 3.91 & $<.001$ \\
\hline Asia & & & $1.22(.51)$ & .34 & 2.42 & .02 \\
\hline
\end{tabular}




\begin{tabular}{lrrrr} 
Wave * Moralizing Beliefs & $1.01(.46)$ & .17 & 2.19 & .04 \\
Wave * Non-Moralizing Beliefs & $-1.75(.61)$ & -.25 & -2.86 & .01 \\
Wave * North America & $.06(.21)$ & .01 & .29 & .77 \\
Wave * South America & $.04(.18)$ & .02 & .25 & .80 \\
Wave * Europe & $.002(.17)$ & .001 & .01 & .99 \\
Wave * Africa & $.06(.22)$ & .01 & .29 & .77 \\
Wave * Asia & $-.07(.18)$ & -.03 & -.41 & .69 \\
\hline
\end{tabular}

Note. Moralizing Beliefs, Non-Moralizing Beliefs, and Wave were centered before analysis. Regional variables were dummy-coded for each country's presence (1) or absence (0) in a geographic region. $R^{2}$ represents the percentage of country-level variation explained.

Table S2

Summary of Multiple Regression Analyses for Variables Predicting Religiosity Over Time.

\begin{tabular}{|c|c|c|c|c|c|c|}
\hline & Participants & $R_{\text {level-2 }}^{2}$ & $b(\mathrm{SE})$ & $\beta$ & $t$ & $p$ \\
\hline Model 1 & 701 & .45 & & & & \\
\hline Decade (Linear) & & & $.17(.21)$ & .12 & .85 & .40 \\
\hline Decade (Quadratic) & & & $.04(.08)$ & .03 & .51 & .61 \\
\hline $\begin{array}{l}\text { Household Moralization } \\
\text { of Religiosity }\end{array}$ & & & $.14(.03)$ & .13 & 3.97 & $<.001$ \\
\hline CREDs & & & $.004(.05)$ & .003 & .08 & .93 \\
\hline Household Religiosity & & & $.32(.05)$ & .30 & 5.93 & $<.001$ \\
\hline Gender & & & $.20(.11)$ & .05 & 1.81 & .07 \\
\hline Age & & & $.01(.01)$ & .04 & 1.57 & .12 \\
\hline Income & & & $-.05(.04)$ & -.04 & -1.29 & .20 \\
\hline $\begin{array}{l}\text { Education } \\
\text { Household Moralization } \\
\text { of Religiosity * Decade } \\
\text { (Linear) } \\
\text { Household Moralization } \\
\text { of Religiosity * Decade }\end{array}$ & & & $.05(.04)$ & .03 & 3.25 & .001 \\
\hline $\begin{array}{l}\text { (Quadratic) } \\
\text { CREDs * Decade }\end{array}$ & & & $.01(.01)$ & .04 & 1.39 & .17 \\
\hline $\begin{array}{l}\text { (Linear) } \\
\text { CREDs } * \text { Decade }\end{array}$ & & & $-.02(.03)$ & -.06 & -.76 & .45 \\
\hline (Quadratic) & & & $.01(.01)$ & .03 & .61 & .54 \\
\hline $\begin{array}{l}\text { Household Religiosity * } \\
\text { Decade (Linear) }\end{array}$ & & & $-.10(.03)$ & -.39 & -3.97 & $<.001$ \\
\hline $\begin{array}{l}\text { Household Religiosity * } \\
\text { Decade (Quadratic) }\end{array}$ & & & $.01(.01)$ & .02 & .50 & .62 \\
\hline
\end{tabular}


Gender * Decade

(Linear)

$\begin{array}{llll}.12(.05) & .15 & 2.40 & .02\end{array}$

Gender * Decade

(Quadratic)

$\begin{array}{llll}.02(.02) & .02 & .76 & .44\end{array}$

Age * Decade (Linear)

$\begin{array}{lllll}-.001(.003) & -.03 & -.24 & .81\end{array}$

Age * Decade

(Quadratic)

$\begin{array}{llll}.0004(.001) & -.002 & -.04 & .97\end{array}$

Income * Decade

(Linear)

$\begin{array}{llll}.01(.02) & .02 & .54 & .59\end{array}$

Income * Decade

(Quadratic)

$\begin{array}{llll}.01(.01) & .02 & .87 & .38\end{array}$

Education * Decade

(Linear)

$\begin{array}{llll}-.02(.02) & -.08 & -1.10 & .27\end{array}$

Education * Decade

$\begin{array}{llll}-.01(.01) & -.05 & -1.34 & .18\end{array}$

(Quadratic)

Note. Decade (Linear) was centered before analyses. $R^{2}$ represents the percentage of participantlevel variance explained.

Table S3

Summary of Multiple Regression Analyses for Variables Predicting Moral Reputation.

\begin{tabular}{|c|c|c|c|c|c|c|}
\hline & Participants & $R_{\text {level-2 }}^{2}$ & $b(\mathrm{SE})$ & $\beta$ & $t$ & $p$ \\
\hline Model 1 & 701 & .56 & & & & \\
\hline Religiosity & & & $.05(.03)$ & .08 & 1.79 & .07 \\
\hline $\begin{array}{l}\text { Household Moralization of } \\
\text { Religiosity }\end{array}$ & & & $-.09(.03)$ & -.11 & -2.64 & .01 \\
\hline $\begin{array}{l}\text { Participant Moralization of } \\
\text { Religiosity }\end{array}$ & & & $-.23(.04)$ & -.29 & -5.93 & $<.001$ \\
\hline $\begin{array}{l}\text { Religiosity } * \text { Household } \\
\text { Moralization of Religiosity }\end{array}$ & & & $.02(.01)$ & .21 & 3.69 & $<.001$ \\
\hline $\begin{array}{l}\text { Religiosity * Participant } \\
\text { Moralization of Religiosity }\end{array}$ & & & $.04(.01)$ & .34 & 6.13 & $<.001$ \\
\hline
\end{tabular}

Note. $R^{2}$ represents the percentage of participant-level variance explained.

Table S4

Summary of Multiple Regression Analyses for Variables Predicting Conjunction Fallacy Errors.

\begin{tabular}{lrrrrrr}
\hline & $d f$ & Adj. $R^{2}$ & $b(\mathrm{SE})$ & $\beta$ & $t$ & $p$ \\
\hline Model 1 & 441 & .29 & & & & \\
Moralization of Religiosity & & & $-.001(.03)$ & -.002 & -.03 & .97 \\
Atheist & & $.15(.16)$ & .14 & .98 & .33 \\
Deconvert & & $-.22(.16)$ & -.21 & -1.38 & .17 \\
Religiosity & & $.004(.02)$ & .01 & .28 & .78 \\
SES & & $.003(.01)$ & .01 & .30 & .76
\end{tabular}


Income

Conservatism

Age

$\begin{array}{rrrr}.01(.02) & .02 & .35 & .72 \\ .01(.01) & .03 & .70 & .48 \\ -.001(.001) & -.02 & -.60 & .55 \\ -.02(.04) & -.02 & -.45 & .65 \\ -.01(.02) & -.01 & -.34 & .74 \\ .10(.03) & .45 & 3.03 & .003\end{array}$

* Atheist

$.10(.04)$

$.45 \quad 2.90$

.004

Note. Atheist and Deconvert variables were dummy-coded to reflect participants' presence (1) or absence $(0)$ in each condition.

Table S5

Summary of Multiple Regression Analyses for Variables Predicting Social Distance from Deconverts.

\begin{tabular}{|c|c|c|c|c|c|c|}
\hline & $d f$ & Adj. $R^{2}$ & $b(\mathrm{SE})$ & $\beta$ & $t$ & $p$ \\
\hline Model 1 & 503 & .16 & & & & \\
\hline Moralization of Religiosity & & & $6.06(.66)$ & .42 & 9.18 & $<.001$ \\
\hline Religiosity & & & $-3.32(.66)$ & -.23 & -5.04 & $<.001$ \\
\hline SES & & & $.58(.49)$ & .06 & 1.18 & .24 \\
\hline Income & & & $-.34(.83)$ & -.02 & -.41 & .68 \\
\hline Conservatism & & & $.44(.40)$ & .05 & 1.08 & .28 \\
\hline Age & & & $.01(.08)$ & .01 & .17 & .86 \\
\hline Gender & & & $.31(1.70)$ & .01 & .18 & .85 \\
\hline Education & & & $.58(.74)$ & .03 & .79 & .43 \\
\hline
\end{tabular}

Table S6

Summary of Multiple Regression Analyses for Variables Predicting the Difference in Social Distance between Deconverts and People who Remain Religious.

\begin{tabular}{|c|c|c|c|c|c|c|}
\hline & $d f$ & Adj. $R^{2}$ & $b(\mathrm{SE})$ & $\beta$ & $t$ & $p$ \\
\hline Model 1 & 503 & .10 & & & & \\
\hline Moralization of Religiosity & & & $3.27(.56)$ & .28 & 5.89 & $<.001$ \\
\hline Religiosity & & & $1.53(.56)$ & .13 & 2.76 & .01 \\
\hline SES & & & $-.23(.41)$ & -.03 & -.56 & .58 \\
\hline Income & & & $1.05(.70)$ & .07 & 1.50 & .13 \\
\hline Conservatism & & & $-.31(.34)$ & -.04 & -.92 & .36 \\
\hline Age & & & $-.08(.07)$ & -.05 & -1.13 & .26 \\
\hline Gender & & & $1.60(1.44)$ & .05 & 1.11 & .27 \\
\hline Education & & & $.67(.62)$ & .05 & 1.08 & .28 \\
\hline
\end{tabular}


Note. Difference scores were calculated by subtracting participants' Social Distance iScores for the target who remained religious from their Social Distance iScores for the deconvert target.

\section{Table S7}

Summary of Multiple Regression Analyses for Variables Predicting the Difference in Social Distance between Deconverts and People who Grow More Religious.

\begin{tabular}{|c|c|c|c|c|c|c|}
\hline & $d f$ & Adj. $R^{2}$ & $b(\mathrm{SE})$ & $\beta$ & $t$ & $p$ \\
\hline Model 1 & 503 & .16 & & & & \\
\hline Moralization of Religiosity & & & $3.67(.57)$ & .30 & 6.49 & $<.001$ \\
\hline Religiosity & & & $2.02(.56)$ & .16 & 3.58 & $<.001$ \\
\hline SES & & & $.03(.42)$ & .004 & .08 & .94 \\
\hline Income & & & $.73(.71)$ & .05 & 1.03 & .31 \\
\hline Conservatism & & & $-.32(.35)$ & -.04 & -.94 & .35 \\
\hline Age & & & $-.11(.07)$ & -.07 & -1.59 & .11 \\
\hline Gender & & & $1.62(1.46)$ & .05 & 1.11 & .27 \\
\hline Education & & & $.66(.63)$ & .05 & 1.05 & .29 \\
\hline
\end{tabular}

Note. Difference scores were calculated by subtracting participants' Social Distance iScores for the target who grew more religious from their Social Distance iScores for the deconvert target.

Table S8

Summary of Multiple Regression Analyses for Variables Predicting Religious Guilt.

\begin{tabular}{lrrrrrr}
\hline & $d f$ & Adj. $R^{2}$ & $b(\mathrm{SE})$ & $\beta$ & $t$ & $p$ \\
\hline Model 1 & 419 & .22 & & & & \\
Condition & & & $1.10(.27)$ & .25 & 4.05 & $<.001$ \\
Participant Religiosity & & & $2.06(.27)$ & .46 & 7.55 & $<.001$ \\
Condition*Participant & & & & & \\
Religiosity & & $-.35(.37)$ & -.07 & -.94 & .35 \\
Model 2 & 456 & .52 & & & & \\
Condition & & & $.38(.16)$ & .08 & 2.41 & .02 \\
Community Warmth & & & $.03(.06)$ & .02 & .47 & .64 \\
Community Religiosity & & & $.73(.04)$ & .71 & 20.22 & $<.001$ \\
Reactance & & & $.03(.05)$ & .02 & .62 & .53 \\
\hline
\end{tabular}

Note. Participant religiosity was measured as either religious (1) or nonreligious (0). All predictor variables are indented below the model. 
Table S9

Summary of Multiple Regression Analyses for Variables Predicting Willingness to Express Doubts.

\begin{tabular}{lrrrrrr}
\hline & $d f$ & Adj. $R^{2}$ & $b(\mathrm{SE})$ & $\beta$ & $t$ & $p$ \\
\hline Model 1 & 419 & .13 & & & & \\
Condition & & & $-1.46(.24)$ & -.39 & -6.12 & $<.001$ \\
Participant Religiosity & & & $-.61(.24)$ & -.16 & -2.53 & .01 \\
Condition*Participant & & & & & \\
Religiosity & & $.28(.33)$ & .07 & .86 & .39 \\
Model 2 & 456 & .24 & & & & \\
Condition & & & $-.93(.17)$ & -.25 & -5.60 & $<.001$ \\
Community Warmth & & & $.15(.07)$ & .10 & 2.13 & .03 \\
Community Religiosity & & & $-.33(.04)$ & -.37 & -8.49 & $<.001$ \\
Reactance & & & $-.07(.05)$ & -.06 & -1.33 & .19 \\
\hline
\end{tabular}

Note. Participant religiosity was measured as either religious (1) or nonreligious (0). All predictor variables are indented below the model.

\section{Table S10}

Summary of Multiple Regression Analyses for Variables Predicting Deconvert Prejudice.

\begin{tabular}{lrrrrrr}
\hline & $d f$ & Adj. $R^{2}$ & $b(\mathrm{SE})$ & $\beta$ & $t$ & $p$ \\
\hline Model 1 & 419 & .13 & & & & \\
Condition & & & $.90(.20)$ & .29 & 4.53 & $<.001$ \\
Participant Religiosity & & & $.69(.20)$ & .22 & 3.41 & $<.001$ \\
Condition*Participant & & & & & \\
Religiosity & & $.02(.27)$ & .01 & .09 & .93 \\
Model 2 & & & & & \\
Condition & 455 & .29 & & & & \\
Community Warmth & & & $.60(.13)$ & .19 & 4.43 & $<.001$ \\
Community Religiosity & & & $-.06(.06)$ & -.05 & -1.03 & .30 \\
Reactance & & & $.34(.03)$ & .47 & 10.82 & $<.001$ \\
\hline
\end{tabular}

Note. Participant religiosity was measured as either religious (1) or nonreligious (0). All predictor variables are indented below the model. 